\title{
ARTICLE
}

\section{Prime Cuts and the Method of Recombination}

\author{
David-Hillel Ruben (D) \\ University of London, London, UK \\ Email: d.ruben@bbk.ac.uk
}

(Received 1 June 2019; revised 12 December 2019; accepted 6 January 2020)

\begin{abstract}
Whether some condition is equivalent to a conjunction of some (sub-) conditions has been a major issue in analytic philosophy. Examples include: knowledge, acting freely, causation, and justice. Philosophers have striven to offer analyses of these, and other concepts, by showing them equivalent to such a conjunction. Timothy Williamson offers a number of arguments for the idea that knowledge is 'prime', hence not equivalent to or composed by some such conjunction. I focus on one of his arguments: the requirement that such conjuncts must be freely recombinable. Although there has been a great deal of discussion of Williamson's arguments, the flaw I describe has gone unnoticed. Williamson's argument is expressed in terms of conditions, and cases of the condition. Does the condition include specific information, or is the specific information only part of the case? His argument equivocates between more and less general specifications of the conditions. Once this distinction is clarified, his argument can be seen to be vitiated by this conflation. Neither option yields a sound argument for Williamson's desired conclusion.
\end{abstract}


is prime, can be shown to be true for some other reason. On that conclusion, I take no stand. ${ }^{1}$

Williamson's view on the primacy of knowledge has been immensely influential, both in epistemology and to some extent, by extension, in action theory. ${ }^{2}$ There have been critics, but no existing criticism of which I am aware has identified the argument's fault that I discuss here. ${ }^{3}$ To buttress the recombination argument, Williamson offers multiple examples. I will treat only one of his examples in full, but its fault is indicative of the underlying problem with his other examples as well. Williamson states his argument in terms of external and internal conditions of an agent, such that they allegedly are the conjuncts of knowing. But the argument is expressed in terms that allow it to be applied to any condition, as a test for the condition being non-composite, or prime (Williamson 2002: 67). Williamson uses 'composite' and 'conjunctive' both as antonyms for 'prime' (2002: 8, 66, 75).

Let condition $\mathrm{C}$ be a conjunction of two (sub-) conditions, D \& E (in fact, we are interested in the case of any number $\mathrm{n}$ of sub-conditions, $\mathrm{n}>1$, but I'll discuss only the case in which there are two (sub-) conditions, for simplicity of exposition.) $\mathrm{C}$ is a complex condition; D \& E are the (relatively) simple (sub-) conditions that are the conjuncts to which $\mathrm{C}$ is equivalent. Williamson's aims to show that knowledge (and many other examples of conditions) are not composite in this sense, because not equivalent to a conjunction of other conditions. (I'm excluding the trivial case in which $C$ is itself one of the conjuncts.) In his parlance, such conditions are prime.

If, for some $\mathrm{D} \& \mathrm{E}$, Williamson can show that $\mathrm{C}$ is not equivalent to $\mathrm{D} \& \mathrm{E}$, it does not follow that $\mathrm{C}$ is a prime condition for at least two reasons: (1) there are other truth functions one might consider (e.g., $\mathrm{C}$ might be a disjunctive condition, as is the condition that something is grue); (2) even if $\mathrm{C}$ is not equivalent to $\mathrm{D} \& \mathrm{E}$, there may be other candidate conjunctions. However, if Williamson's argument against a specific and initially plausible conjunctive decomposition of a condition into (sub-) conditions is successful, that must lend some credibility to the claim that $\mathrm{C}$ is prime. Presumably it would depend on whether there are other plausible candidates to be the conjuncts that compose $\mathrm{C}$, and whether there are other plausible truth functions to be considered.

Let me start by setting out the logic of Williamson's argument and the point of my reply to it. His argument is this: suppose some condition $C$ were composed of two (sub-) conditions, D \& E. If $\mathrm{C}$ were composed of $\mathrm{D} \& \mathrm{E}$, then $\mathrm{C}, \mathrm{D}$, and $\mathrm{E}$ would have to pass a certain test: Williamson calls it 'the recombination test'. But suppose further that $\mathrm{C}, \mathrm{D}, \& \mathrm{E}$ fail that recombination test. If so, $\mathrm{C}$ cannot be composed of $\mathrm{D} \& \mathrm{E}$ after all. Williamson's argument has the form of a reductio.

Williamson's argument is expressed in terms of conditions and cases of the condition. First, what is a case? Williamson says this: 'A case is a possible total state of a system, the system consisting of an agent at a time ... A case is like a possible world, but with a distinguished subject and time ... Different cases can distinguish different subjects and times' (2002: 52). It's a possible world centered on a particular subject at a

\footnotetext{
${ }^{1}$ The only other discussion I know of the criteria for deciding when a condition is basic or not, is in Tooley (1987: 24-9).

${ }^{2}$ Williamson himself has developed the analogy between knowledge and action, first suggesting it in Knowledge and its Limits (2002: 6-8), and then further developing it in his 'Acting on Knowledge' (2017). See also for example Yair Levy (2013), Richard Holton (2015) and Lucy O’Brien (2017).

${ }^{3}$ See Anthony Brueckner (2002) and Adam Leite (2005), and reviews by Brueckner (2005), Earl Conee (2005), John Hawthorne (2005) and Stephen Yablo (2005). Replies by Williamson (2005), Patrick Greenough (2009), Aidan McGlynn (2014) and Carter et al. (2017) and the review of Williamson by Hannes Leitgeb (2002).
} 
particular time (Williamson refers to Lewis' idea of a centered world). ${ }^{4}$ Since a possible world is a way in which things could be, a case is a total way in which things could be, at a time and for an agent. A case must be maximally specific; it states everything that is true from that agent's perspective at that time (and in that world).

What is a condition? A condition 'obtains or fails to obtain in each case. Conditions are specified by 'that' clauses ... Thus, the condition that one is happy obtains in case $\alpha$ iff in $\alpha$ the agent is happy at the time of $\alpha .{ }^{5}$ A condition specifies some particular way in which the agent is at the time of $\alpha$. If a case is a total possible state of a system, a condition is some particular way (like being happy) in which things are at some time for some agent. Conditions are coarsely individuated (94): condition $\mathrm{C}=$ condition $\mathrm{C}^{\star}$ iff $\mathrm{C}$ and $\mathrm{C} *$ hold in exactly the same cases. They are also unlike propositions, since they are 'open with respect to person, place, and perhaps other circumstances too.' Conditions are such that they may be or may fail to be composite, or prime.

An important requirement of the idea of the equivalence of a condition to a conjunction of (sub-) conditions, a requirement that Williamson makes much of, is the idea of free recombination, which I mentioned earlier. Williamson argues that if condition C were composed of conditions D \& E, then we should be able to 'freely recombine' D \& $\mathrm{E}$ in different cases, taking $\mathrm{D}$ from one case and $\mathrm{E}$ from a second case, and still have condition $\mathrm{C}$ in a third case in which they are recombined. There will be much more on this later.

In order to show how this works, I want to begin by focusing on the last example in Williamson's list (2002: 69-72): knowledge by testimony. Suppose a philosopher proposes that the condition that someone has knowledge that $\mathrm{p}$ by testimony is equivalent to the condition that that person believes that $\mathrm{p}$ by hearing that $\mathrm{p}$ from a trustworthy person whom he trusts. (Whatever reservations one might have about such an account of knowledge by testimony are not relevant here; this is Williamson's own example, used by him as an illustration of his account of what it is for a condition to be prime. For a start, one would have to add another sub-condition about the truth of p.) Others have pointed out that the description of the example in terms of two independent (sub-) conditions, D \& E, omits the causal element that is implicit in the example, that one's belief that $\mathrm{p}$ is caused by what the trustworthy person says, and which thereby links the two (sub-) conditions. ${ }^{6}$ That criticism is sound but it is not the criticism that I want to make in this paper. My criticism is different.

Suppose the proposal that is being considered is this: the condition $C$ is that a person $\mathrm{P}$ knows that $\mathrm{p}$ by testimony, and that $\mathrm{C}$ is a conjunction of: $\mathrm{D}$, that $\mathrm{P}$ is told that $\mathrm{p}$ by a trustworthy person and $\mathrm{E}$, that $\mathrm{P}$ trusts what the person says. (As I have already said, we would have to add sub-conditions about truth and causal connection, but let's disregard those complications as being irrelevant to the argument here.) As part of the example, we are meant to assume that $\mathrm{P}$ has no other way of knowing that $\mathrm{p}$. In what follows, I continue to use ' $\mathrm{P}$ ' as a placeholder for some person's proper name, and ' $\mathrm{p}$ ' is just the dummy name for any proposition. (I take it that if $\mathrm{P}$ trusts what a person says, he believes what that person says.) Here is Williamson's argument:

${ }^{4}$ See Lewis (1979) and Liao (2012). But the idea of an agent-centered world has its own difficulties and is unlikely to illuminate Williamson's use of the concept of a case.

${ }^{5}$ Alternatively, one could also think of conditions as states of affairs, e.g., someone's being happy.

${ }^{6}$ Brueckner (2005); Leitgeb (2002: 199): 'if I am told that the election was rigged, then my corresponding belief is knowledge only if one and the same testimonial source is simultaneously trustworthy and being trusted; knowledge in this case entails that there is a certain relationship between my internal state of trusting and the external state of someone's being trustworthy ...' 
(i): In the first case, Smith is trustworthy and Brown is not, and P trusts Smith but not Brown. In such a case, if both Smith and Brown tell $\mathrm{P}$ that $\mathrm{p}, \mathrm{P}$ knows by testimony that $\mathrm{p}$, because $\mathrm{P}$ is told that $\mathrm{p}$ by Smith, who is a trustworthy person, and $P$ trusts Smith.

(ii): In the second case, Brown is trustworthy and Smith is not, and P trusts Brown but not Smith. In this case, when both Smith and Brown tell $\mathrm{P}$ that $\mathrm{p}, \mathrm{P}$ knows by testimony that $\mathrm{p}$ because $\mathrm{P}$ is told that $\mathrm{p}$ by Brown, who is a trustworthy person, and $\mathrm{P}$ trusts Brown.

In both cases, (i) and (ii), condition $\mathrm{C}$ obtains. Person $\mathrm{P}$ in both cases trusts a trustworthy person, and so has knowledge by testimony that $\mathrm{p}$ (given the account of knowledge by testimony that Williamson is using).

Now consider a third and fourth cases: (iii) and (iv):

(iii): In the third case, Brown is trustworthy and Smith is not, but $\mathrm{P}$ trusts Smith but not Brown. In this case, when both Smith and Brown tell $\mathrm{P}$ that $\mathrm{p}, \mathrm{P}$ does not know by testimony that $\mathrm{p}$, because $\mathrm{P}$ has not trusted a trustworthy person.

(iv): In the fourth case, Smith is trustworthy and Brown is not, but P trusts Brown and not Smith. In this case too, when both Smith and Brown tell P that $\mathrm{p}, \mathrm{P}$ does not know by testimony that $\mathrm{p}$, because he has not trusted a trustworthy person. In neither case (iii) nor case (iv) does it follow that the person is in $\mathrm{C}$, that he has knowledge by testimony. Why is this a problem for the alleged equivalence of $\mathrm{C}$ and the conjunction, $\mathrm{D} \& \mathrm{E}$ ?

'Suppose that C obtains in two cases', (i) and (ii). Consider another case, say (iii), which is like case (i), in which P trusts Smith but not Brown but is like case (ii) in which Brown but not Smith is trustworthy (I am paraphrasing Williamson 2002: 67). If C is the conjunction of $\mathrm{D}$ and $\mathrm{E}$, then $\mathrm{C}$ must obtain in (iii) (and (iv)). Why? Williamson relies on the principle of free recombination to show this. If $\mathrm{C}$ is the conjunction of D \& E, then C entails D in case (ii). But case (iii) is exactly like (ii) in regard to who is trustworthy; so D obtains in (iii) as well. Similarly, since C entails E, E obtains in case (i). But case (iii) is exactly like (i) in respect of whom P trusts, so E obtains in (iii) as well. So if $\mathrm{C}=\mathrm{D} \& \mathrm{E}$, then $\mathrm{C}$ should obtain in (iii) and (iv) too. But it does not.

$\mathrm{P}$ does not have knowledge by testimony in (iii), because in (iii) $\mathrm{P}$ has trusted an untrustworthy person. $C$ does not obtain in (iii), so $C \neq D \& E$. And the same can be said for case (iv). On Williamson's argument, this shows that e.g. knowing by testimony is not a conjunctive state or condition, $\mathrm{C}$, 'factorable' into two metaphysically independent conjuncts, D and E. It is, in his words, prime (assuming no better candidate truth functions or candidate conditions present themselves).

Let's be more precise about which condition is condition $\mathrm{C}$ in these examples, and which conditions, $\mathrm{D} \& \mathrm{E}$, are the ones from which is $\mathrm{C}$ allegedly composed. There is an ambiguity in the recombination argument as presented. Let's identify the ambiguity, at least in Williamson's case of knowledge by testimony, as being between a relatively more general and a relatively more specific condition (on Williamson's individuation criterion for conditions, that will of course produce two different conditions). The less general condition will include additional information about Smith and/or Brown; the more general content will omit all mention of any particular people. Let's call a condition with the additional contents about particular people 'a less general condition' or 'a more specific condition'; a condition with no mention of particular people, 'a more general condition' or 'a less specific condition'. 
A more general condition which contains less information is logically weaker; a more specific condition which contains a greater amount of information is logically stronger, in the sense that the more specific condition might entail the more general one, but the more general one cannot entail the more specific one. For example, the condition that Brown told $\mathrm{P}$ that $\mathrm{p}$ is more specific than the condition that someone told $\mathrm{P}$ that $\mathrm{p}$. So the former entails the latter, but the latter does not entail the former. My paradigm for this distinction is, for example, the relationship between the condition of being an apple and the condition of being a red apple. In that paradigmatic case, (a) degree of specificity, (b) amount of included information, and (c) logical strength travel in the same direction. Should one want a more general account of this distinction, consideration would need to be given to cases other than my simple paradigm, e.g., a disjunction and one of its disjuncts. But there is no need to do that further work for my purposes here.

So now we can pose a dilemma. Is condition $\mathrm{C}$ the less general condition, (a) that $\mathrm{P}$ knows that $\mathrm{p}$ by testimony from Smith (or from Brown or from Brown or Smith), or is $\mathrm{C}$ the more general condition (b) that $\mathrm{P}$ knows that $\mathrm{p}$ by testimony (full stop)? The first horn of the dilemma, (a), uses additional information from the case in identifying the condition. The second horn, (b), leaves that additional information to the specification of the case, but without building it into the identification of the condition.

However we reply to this dilemma, it is clear that $\mathrm{C}, \mathrm{D}$, and $\mathrm{E}$ must match in degree of specificity or generality. If $\mathrm{C}$ is more general, and $\mathrm{D} \& \mathrm{E}$ is more specific, $\mathrm{C}$ could not entail $\mathrm{D} \& \mathrm{E}$. If $\mathrm{C}$ is more specific but $\mathrm{D} \& \mathrm{E}$ are more general, then $\mathrm{D} \& \mathrm{E}$ could not entail C. If all we know is that $\mathrm{P}$ has knowledge by testimony, full stop, that can't entail anything about the trustworthiness of any particular people (Brown or Smith), or anything about whom in particular (Brown or Smith) P trusts. On the other hand, if $\mathrm{P}$ has knowledge by testimony from some particular persons, Brown or Smith, that can't be entailed by any information about trust and trustworthiness, but which omits all mention of either of Brown or Smith.

(a) is the option of making the condition $\mathrm{C}$ more specific, containing information about particular trustees. $\mathrm{C}$ might be: that $\mathrm{P}$ knows that $\mathrm{p}$ by testimony from Smith (or from Brown or from Brown or Smith). If so, what would D \& E look like? Each of the (sub-) conditions D \& E will have to have more specific informational content as well. If they weren't more specific, D \& E could not entail C. D might be: that $\mathrm{P}$ trusts Smith (or trusts Brown or trusts Smith or Brown), and E might be: that Smith (or Brown or (Smith or Brown)) is trustworthy. As far as I am aware, no epistemologist has ever thought that their goal was to give accounts of such highly specific conditions. We would need different analyses for each such specific condition, as the conditions related to different individual trustworthy or trusted persons.

less informational content, and preserve the match in level of informational spe-

cificity between condition and (sub-) conditions, so that both the conditions and the (sub-) conditions omit the more specific informational content. There is evidence that (b) is what Williamson has in mind, since as we saw above, he has told us that conditions are 'open with respect to person, place, and perhaps other circumstances too'. And that is of course the form in which philosophy has always addressed questions of analysis. For example, in 'P knows that p', both ' $\mathrm{P}$ ' and ' $\mathrm{p}$ ' are simply dummy names for any person and any proposition, n'import quelle. No specific person or proposition is 
being envisaged. Or, in 'c causes e', 'c' and 'e' are just placeholders for any two events. No specific cause or effect is under consideration.

But (b), sensible as it is, would make Williamson's method of recombination inoperable. Nothing in Williamson's argument so construed would show whether or not C is composed of D \& E. Williamson's employment of the method of recombination required that the content of both conditions D \& E had a specific content, about Smith or Brown being trusted or being trustworthy. That is, Williamson's recombination argument, in order to work, requires that we build into the analysis's (sub-) conditions themselves the information about Smith or Brown taken from the description of the cases, but if so, such more specific (sub-) conditions couldn't be entailed by the construal of the analysandum, $\mathrm{C}$, on option (b) of the dilemma.

The fault in the argument is a conflation between information that belongs to the cases and the information that is built into the specification of the conditions. (I think the example from Leite, in what follows, will make the conflation between information about the case on the one hand, and the content of the condition, on the other, even more salient.) To sum up, if, on (b), condition $\mathrm{C}$ is more general, then either the (sub-) conditions are as equally full or general as $\mathrm{C}$, in which case there is nothing in them (nothing about Smith or Brown) to recombine, or the (sub-) conditions are more specific than $\mathrm{C}$ (with specific information about Smith or Brown in them), in which case $\mathrm{C}$ can't entail them.

On option (b), are there other ways in which to identify D \& E, that both eliminate such specific information but at the same time also permit recombination? Perhaps D could be: that P trusts someone who says that p; and E could be: that that person [viz., whoever says that $\mathrm{p}$ in (sub-) condition $\mathrm{D}$ ] is a trustworthy person. Taken in that way, $\mathrm{P}$ will never trust an untrustworthy person. Information specifically about its being Brown or Smith who is trustworthy is consigned to collateral information about the case and forms no part of the conditions. On this option, C, D, and $\mathrm{E}$ all match in degree of specificity. They are all relatively general. Might $\mathrm{C}$ now be equivalent to the conjunction, $\mathrm{D} \& \mathrm{E}$ ?

However, the content of E contains an indexical, 'that person', which refers to whichever person it is that is mentioned in D. In case (i), in which it is Smith who is trustworthy (i.e., in D), Smith is that person whom $\mathrm{P}$ trusts (i.e., in E). In case (iii), in which Brown is trustworthy, 'that person' in E now refers to Brown, who now figures also in (D) in case (iii), and not to Smith. The indexical in E shifts its reference in line with the change of person in D. In order for Williamson's argument to conclude that $\mathrm{C}$ fails to be the case in (iii), it would require that $\mathrm{E}$ in case (iii) be about Smith, as it was in case (i); it would have to be Smith who is being trusted. But E in case (iii) is not about Smith. It is about Brown. So understood, $\mathrm{P}$ does have knowledge by testimony in (iii) and (iv) after all, so Williamson's argument fails to demonstrate his conclusion. ${ }^{7}$

\footnotetext{
${ }^{7}$ But must some appropriate indexical occur within the content of either D or E? Another possibility might be this. $\mathrm{D}$ : that $\mathrm{P}$ is told by someone trustworthy that $\mathrm{p}$; $\mathrm{E}$ : that $\mathrm{P}$ believes what he has been told (namely that p). There are no indexicals in this proposal. But that latter proposal won't constitute knowledge by testimony even in (i) or (ii), let alone in (iii), on anyone's view, unless something more is added to E about who told you that $\mathrm{p}$, because you might have been told by a trustworthy person that $\mathrm{p}$ but believe that $\mathrm{p}$ only because you were also told that $\mathrm{p}$ by a different and untrustworthy person, or only because the belief merely occurred to you, for no particular reason. The case is one in which we assume that $\mathrm{P}$ has no other way of knowing that $\mathrm{p}$, but that assumption does not rule out $\mathrm{P}$ believing that $\mathrm{p}$ for some other reason, or for none. It is here for example where the need to impose a causal condition, linking D and E arises, but it is hard to see how to do this without making free recombination impossible.
} 
Perhaps an existential generalisation will solve the problem just identified: $\mathrm{P}$ knows that $\mathrm{p}$ by testimony iff $(\exists \mathrm{x})$ ( $\mathrm{P}$ trusts $\mathrm{x} \& \mathrm{x}$ is trustworthy). I have no reason, as far as this paper is concerned, to dispute such a proposal. However, Williamson's target is the idea that knowledge is a conjunction, as opposed to the idea that it is an existential generalisation with a conjunction inside of it. In terms of the dialectic of this argument, such an alternative proposal is not available to Williamson. What Williamson wants is a proposal that provides freely recombinable (sub-) conditions, D \& E, in order to show that there is a circumstance in which one can be in some condition that is a recombination of them and still not be in the general condition C. If one binds the free variables by a quantifier whose scope is the whole conjunction, the (sub-) conditions in the conjunction are no longer independent of each other. It will no longer be possible to detach them from one another and then recombine them differently in another case.

So there is the dilemma: (b) either the condition $\mathrm{C}$ we are asking about is relatively general (so that the specific, additional information about the case is not included in the conditions but remains only as collateral information about the case) or (a) the condition $\mathrm{C}$ is relatively more specific (so that the conditions themselves include the more specific additional information and so are no longer 'open'). But on neither horn of the dilemma will Williamson's argument show anything about conditions not composing or failing to be the conjuncts of other conditions.

Williamson uses the same argument structure with other examples. His vision example uses the right-eye and the left-eye; in the auditory case, there are two sound frequencies, frequency $f$ and frequency $g$. In the case of the growling tigers, there is a mountain-inhabitor and a jungle-inhabitor. Other of his examples include: the conjunction of a specific colour and a specific shape property; that one sees water; that one believes that this screen flickers; that one believes that tigers growl. All of his examples follow the same pattern; all rely on additional specific information in at least one of the alleged (sub)-conditions and the same dilemma sketched above will apply in these examples too.

Leite (2005) offers what he says is a counterexample to Williamson's claim of how to demonstrate that a condition is prime. I rely on my, Leite's, and hopefully the reader's, intuition, that this example is clearly a case of a condition that is composed of a conjunction; any argument on which this example turns out to be prime, must be flawed in some way. Leite produces the counterexample, and says that 'Let us grant that this example succeeds' (2005: 171). Leite's view is that Williamson's recombination argument does succeed, both in Williamson's original example of knowledge by testimony and in his new example, but that this shows us nothing about whether or not 'any particular case of knowing is a complex state' (2005: 170). My view, unlike Leite's, is that the recombination argument does not succeed. The ambiguity I identified above allowed us to see why the recombination argument failed for knowledge by testimony and it will allow us to see why the argument also fails for the case that Leite uses.

Leite says that driving lawfully, $(\mathrm{C})$, is a conjunctive condition composed of how one is driving (D) and how the law says one should drive (E), and that the example shows that Williamson's recombination test cannot discriminate between prime and composed conditions.

(i): A (drives on the right); $\mathrm{B}$ (the law says drive on right).

(ii): D (drives on the left); $\mathrm{E}$ (the law says drive on left).

(iii): A (drives on right); $\mathrm{E}$ (the law says drive on the left).

(iv): B (the law says drive on right); D (drives on left). 
conjunctive conditions, being in A \& E or in B \& D, do not place one in condition C, driving lawfully. Let me restate Leite's example in terms of my own diagnosis.

Ask yourself: which law is it to which 'the law' refers to in the conditions above? Making that clear by making the conditions more precise will give us:

(i): A (drives on the right in USA); B (US law says drive on right).

(ii): D (drives on the left in UK); E (UK law says drive on left).

(iii): A (drives on right in USA); E (UK law says drive on the left).

(iv): B (US law says drive on right); D (drives on left in UK).

First, if condition C were (just) the more general ('open') condition, i.e., that one is driving lawfully (as Leite says at the beginning of his example), then, given that we need to match levels of generality/specificity, no specific reference should be made in $A, B, D$, and E to 'USA law' or 'UK law' or 'on the right' or 'on the left'. The best we could do is to say that driving lawfully is driving on whichever side of the road that the law of wherever one is driving says to drive. But as we saw before, a Williamson style counterexample to its being a conjunctive condition would then fail, because of the shift of reference of both 'side of the road' and 'the law' across the different cases. On the other hand, consider the more specific content description option for the conditions A, B, D, and E, which uses additional information. A \& B might then indeed compose $\mathrm{C}$, driving lawfully in the USA, and D \& E might compose a different condition $C^{\star}$, driving lawfully in the UK, but again those four (sub-) conditions, A, B, D, and E, are not freely recombinable, because each set of two (sub-) conditions (A \& B on one hand, D \& E on the other) composes a different condition, either $C$ or $C^{\star}$. $C \neq C^{\star}$. There is no single condition $C$ that both $\mathrm{A} \& \mathrm{~B}$, and $\mathrm{D} \& \mathrm{E}$, compose in all the various cases.

Here is an analogy. A vixen is a female fox (call it ' $\mathrm{V}$ '). A bachelor is an unmarried adult male (call it 'B'). No one would be tempted to argue that the concepts of a vixen (V) and a bachelor (B) are not composites, because one can't recombine the concept of a fox from $\mathrm{V}$ and the concept of being unmarried from B and thereby obtain either V or B. An unmarried fox is neither a bachelor nor a vixen. The mistake would be the same in both the vixen-fox case and the second option for the analysis of lawful driving above. Just as the concept of a vixen $\neq$ the concept of a bachelor, so too $C \neq C^{*}$. No recombination argument can even get started when we are dealing with different concepts.

Is there some general lesson we can draw from this about how one can show whether or not a condition is prime? What lesson can we draw about the method of free recombination as such a test? If we step back for a moment from the detail of Williamson's argument, we can see, I think, what has gone wrong. Suppose, to use our stock example again, that someone proposes that condition $\mathrm{C}$ (e.g., that c causes e) is a conjunction of two other conditions, D \& E (that c precedes e; that $\mathrm{c}$ and e are spatially and temporally contiguous). Again, we consider three cases. In order to fairly evaluate the proposal, C, $\mathrm{D}$, and $\mathrm{E}$ must remain similarly more general or more specific. They must match in terms of degree of generality/specificity (or, logical strength). As I have already stressed, the tradition of analysis has always assumed generality. It is entirely unclear what role there is for the idea of cases to play. Suppose that one does consider three cases. In two of those cases, something that is C is also D \& E. But in a third case, D \& E obtain but not C. What should we conclude? Certainly, we should conclude that $\mathrm{C}$ is not composed by (or equivalent to) $\mathrm{D} \& \mathrm{E}$.

But three cases, and Williamson's recombination test, are otiose. If 'D' and 'E' are used ambiguously for different conditions in the different cases, then there is no single condition $\mathrm{C}$ that their combinations compose. And therefore there will be no recombination on offer. As long as each of $\mathrm{C}, \mathrm{D}$, and $\mathrm{E}$ refers to the same condition in all the 
cases, if there were $a$ single case in which something is not in condition $\mathrm{C}$ but were in the conjunctive condition $\mathrm{D} \& \mathrm{E}$, it follows that $\mathrm{C}$ cannot be equivalent to the conjunction $\mathrm{D} \& \mathrm{E}$ (in any of the cases), because the conjunction isn't sufficient for C. (Or, if something is in $\mathrm{C}$ but not $\mathrm{D} \& \mathrm{E}$ in one case, $\mathrm{C}$ can't be sufficient for the conjunction in any of the cases.) Adding 'in any case' or 'in a single case' is strictly redundant. A condition can't fail to be sufficient or necessary or equivalent to another condition in one case but not in another. It can only be insufficient or unnecessary or neither, full stop. That's what sufficiency or necessity of conditions means.

Introducing cases is otiose. It might be, of course, that $\mathrm{C}$ and $\mathrm{D} \& \mathrm{E}$ happen to co-occur in some cases but not in others, but such co-occurrence of conditions does not arise because of any alleged equivalence between them in one case but not in another. The co-occurrence may arise as a matter of mere happenstance. Or there could be co-occurrence in some cases but not others, because condition $\mathrm{C}$ is necessary but insufficient, or sufficient but unnecessary, for the conjunction. It may well be that in some cases in which two events, $\mathrm{c}$ and $\mathrm{e}$, are related by temporal precedence and spatialtemporal contiguity, those two events also stand in a causal relation. But there certainly won't be any equivalence if there is any case in which they stand in those first two relations but not the causal relation, or in which they stand in the causal relation but not in one or both of the other two relations.

It is therefore entirely misleading for Williamson to write about the first two cases (for example): 'since C obtains whenever [my italics] both D and E obtain ...' (2002: 68). In fact, there is only one sure-fire way in which to show that $\mathrm{C}$ is not equivalent to the conjunction of D \& E, and that way has been the method of philosophy since its inception: find any case, actual or merely metaphysically (or conceptually) possible, in which $\mathrm{C}$ obtains but at least one of $\mathrm{D} \& \mathrm{E}$ does not, or in which $\mathrm{D} \& \mathrm{E}$ both obtain but $\mathrm{C}$ does not. This sure-fire way can be couched in the language of equivalence between sentences, propositions, or whatever, or it can be couched (as it is in Williamson) in the language of conditions and their equivalence to a conjunction of other conditions. But that is hardly news for which we needed Williamson's methodology of cases and recombination.

\section{References}

Brueckner A. (2002). 'Williamson on the Primeness of Knowing.' Analysis 62(3), 197-202.

Brueckner A. (2005). 'Knowledge, Evidence, and Skepticism According to Williamson.' Philosophy and Phenomenological Research 70(2), 436-43.

Carter J.A., Gordon E.C. and Jarvis B.W. (eds) (2017). Knowledge First: Approaches in Epistemology and Mind. Oxford: Oxford University Press.

Conee E. (2005). 'The Comforts of Home.' Philosophy and Phenomenological Research 70(2), 444-51.

Greenough P. (ed.) (2009). Williamson on Knowledge. Oxford: Oxford University Press.

Hawthorne J. (2005). 'Knowledge and Evidence.' Philosophy and Phenomenological Research 70(2), 452-8.

Holton R. (2015). 'Crime as Prime.' Law and Ethics of Human Rights 9, 181-93.

Leite A. (2005). 'On Williamson's Arguments that Knowledge is a Mental State.' Ratio New Series XVIII, $165-75$.

Leitgeb H. (2002). 'Review of Timothy Williamson, Knowledge and its Limits.' Grazer Philosophische Studien 65, 195-205.

Levy Y. (2013). 'Intentional Action First.' Australasian Journal of Philosophy 91(4), 705-18.

Lewis D. (1979). 'Attitudes de dicto and de se.' Philosophical Review 88, 513-43.

Liao S.-Y. (2012). 'What Are Centered Worlds?' Philosophical Quarterly 62(247), 294-316.

McGlynn A. (2014). Knowledge First? London: Palgrave Macmillan. 
Williamson T. (2005). Replies. Philosophy and Phenomenological Research 70, 468-91.

Williamson T. (2017). 'Acting on Knowledge.' In J.A. Carter, E.C. Gordon and B.W. Jarvis (eds), Knowledge First: Approaches in Epistemology and Mind. Oxford: Oxford University Press.

Yablo S. (2005). 'Prime Causation.' Philosophy and Phenomenological Research 70(2), 459-67.

David-Hillel Ruben has a BA from Dartmouth College (USA) and a PhD from Harvard University. He began his career at the University of Edinburgh as tutor and subsequently has held lectureships at Glasgow, Essex, and City Universities. He was made a professor at the LSE in 1994 and has been at

Cite this article: Ruben D-H (2020). Prime Cuts and the Method of Recombination. Episteme 1-10. 